A. Błażejewski, T. Krzyżyński

Zakład Mechatroniki i Mechaniki Stosowanej, Politechnika Koszalińska 75-620

Koszalin, ul. Racławicka 15-17, Poland

\title{
IDENTYFIKACJA OBIEKTU WIBROAKUSTYCZNEGO ZA POMOCĄ MODELI NIEPARAMETRYCZNYCH
}

\begin{abstract}
STRESZCZENIE
W pracy przedstawiono przykład identyfikacji obiektu wibroakustycznego na przykładzie głośnika niskotonowego zestawu głośnikowego ALTUS. Zaprezentowano opis badanego obiektu za pomocą trzech modeli nieparametrycznych: transmitancji widmowej, funkcji korelacji oraz gęstości widmowej.
\end{abstract}

Key words: transmitancja, gęstość widmowa, funkcja korelacji.

\section{WSTĘP}

Proces identyfikacji można określić jako próbę opisania za pomocą aparatu matematycznego zachowania się wybranego obiektu, procesu lub całego systemu. W sytuacjach, gdy nie posiadamy dostatecznej wiedzy na temat wewnętrznych relacji między strukturami wewnątrz, a co za tym idzie nie możemy dla nich napisać prostych równań matematycznych lub, gdy opis ten jest bardzo skomplikowany, a i tak przybliżony, bo najczęściej zrealizowany za pomocą nieliniowych, niestacjonarnych, cząstkowych równań różniczkowych o parametrach rozłożonych, wykorzystujemy metody polegające na znalezieniu jak „najwierniejszy” relacji między wejściem i wyjściem obiektu, procesu lub systemu. Jeżeli znane są wielkości wejściowe, które stanowią argumenty funkcji opisującej obiekt oraz wielkości wyjściowe stanowiące wartości tej funkcji możemy wykorzystać analizę statystyczną do opisania obiektu modelem stochastycznym. Model taki estymuje jedynie zależności między wejściem i wyjściem, lecz jeżeli błąd tej estymacji jest dopuszczalny, można wykorzystać go w identyfikacji. Proces poszukiwania modelu stochastycznego powinien zawierać następujące, główne etapy $[1,2,3]$ :

- Określenie celu (dokładność modelu, jego przeznaczenie, wielowymiarowość (SISO, MIMO) oraz istotnych zmiennych (sygnały wejściowe i wyjściowe);

- Wybór klasy modelu (parametryczny - transmitancja operatorowa, równania stanu, nieparametryczne - funkcja wagi, odpowiedź skokowa, transmitancja widmowa, funkcja korelacji) i związaną z tym metodą identyfikacji (funkcja strat) wynikającą z posiadaną wiedzą a priori np. o zakłóceniach;

- Eksperyment (rodzaj i poziom sygnałów wejściowych, próbkowanie, filtracja, usunięcie trendów) lub zebranie i analiza wcześniej wykonanych pomiarów; 
- Wybór numerycznej procedury do określenia minimum funkcji strat (pakiety Statistica, Matlab System Identification, Neural Network);

- Weryfikacja modelu polegająca na porównaniu wyników (sygnałów wyjściowych)

z modelu z wynikami otrzymanych z identyfikowanego obiektu przy takim samym pobudzeniu (sygnałach wejściowych) przy określonym poziomie błędów.

\section{BADANY OBIEKT}

W pracy przedstawiono identyfikację obiektu wibroakustycznego. W dowolnym obiekcie wibroakustycznym wymuszeniem może być dowolne źródło energii mechanicznej np. pracujące silniki, elektromagnetycznej urządzenia elektryczne takie jak transformatory, powodujące generowanie i propagację w otaczającym ośrodku fali akustycznej. Jako przykład takiego obiektu wykorzystano głośnik niskotonowy GDN30-80-8 zestawu ALTUS 300. W celu uzyskania sygnału pobudzającego tylko na jednym głośniku, zwrotnice w zestawie zostały rozłączone. Na wejście jako pobudzenie podawano poprzez wzmacniacz Brüel \& Kjær typu 2718 sygnał napięciowy $\mathrm{z}$ generatora kasety pomiarowej 3560C tej samej firmy. Wielkością obserwowaną (mierzoną) na wyjściu była prędkość drgań membrany głośnika, mierzona wibrometrem laserowym typu OMETRON VH 300+. Prędkość drgań, poprzez impedancję akustyczną, związana jest z wielkościami akustycznymi: ciśnieniem akustycznym i natężeniem dźwięku. Obiekt, w którym wielkości (sygnały) wejściowe są szeregami czasowymi jest obiektem dynamicznym. Ze względu na ilość wejść i wyjść jest to obiekt typu SISO, czyli o jednym wejściu i jednym wyjściu. Z zastosowanych poziomów sygnału wejściowego wiadomo, że nie ma on wpływu na parametry obiektu i można uważać go za liniowy w całym badanym zakresie.

\section{METODYKA BADAŃ}

W celu identyfikacji obiektu wibroakustycznego emitującego zazwyczaj stacjonarną falę w szerokim zakresie częstotliwości, można zastosować modele parametryczne, dające zwarty zapis w postaci skończonych wektorów parametrów, określających stan obiektu. Aby wybrać właściwą strukturę modelu parametrycznego musimy dysponować dodatkową widzą na temat charakteru i dynamiki obiektu [4]. W tym celu właściwe jest wcześniejsze zbadanie obiektu, czyli jego identyfikacja przy zastosowanie łatwiejszych w użyciu modeli nieparametrycznych dających opis w postaci wykresów, tabel lub funkcji. Pośród wielu modeli nieparametrycznych mogących dostarczyć informacji na temat badanego obiektu, procesu lub systemu ważny jest wybór takiego, który najwierniej odzwierciedla warunki ,naturalnej pracy”. W zawiązku z powyższym w pracy nie koncentrowano się na procesach przejściowych, które najlepiej opisują: odpowiedź impulsowa oraz skokowa obiektu, a wybrano analizę częstotliwościową (transmitancja widmowa) oraz widmową (funkcja korelacji i gęstość widmowa). Pierwsza z nich opisuje zachowanie się układu na wymuszenie harmoniczne dla każdej częstotliwości z badanego zakresu. Druga, charakteryzuje związek między losowymi, 
przesuniętymi w czasie sygnałami wejściowym i wyjściowym. Na podstawie funkcji korelacji można następnie wyznaczyć gęstość widmową, czyli „dystrybucję” energii sygnału w widmie częstotliwości. W przypadku obu typów modeli najlepszym sygnałem wejściowym, zastosowanym $\mathrm{w}$ eksperymencie, jest sygnał o charakterze „białego szumu”. Pobudza on wszystkie mody obiektu oraz spełnia warunek proporcjonalności funkcji korelacji wzajemnej w stosunku do odpowiedzi impulsowej obiektu. Współczynnikiem proporcjonalności jest wariancja sygnału pobudzającego $[2,3]$. W procesie identyfikacji generowano „biały szum” o wartości oczekiwanej zero i wariancji 0,0095 oraz ze względu na pasmo przenoszenia głośnika, ograniczony filtrem dolnoprzepustowym 1,6kHz. Sygnały próbkowano z częstotliwością 4096Hz.

\section{TRANSMITANCJA WIDMOWA}

Transmitancja widmowa jest podstawowym modelem identyfikacji stacjonarnych obiektów liniowych. Model ten charakteryzuje się dwoma parametrami: wzmocnieniem sygnału pobudzającego oraz przesunięciem fazowym. W ten sposób określana jest dynamika obiektu $\mathrm{W}$ zależności od częstotliwości sygnału pobudzającego. Transmitancja widmowa $G(j \omega)$ jest funkcja zmiennej zespolonej $s=j \omega$, gdzie $\omega$ jest częstością wymuszenia. Transmitancja widmowa jest granicą transmitancji operatorowej (1), czyli jednego z modeli parametrycznych [2,3]:

$$
G(j \omega)=\lim _{s \rightarrow j \omega} G(s)
$$

Oryginałem transmitancji widmowej w dziedzinie czasu jest odpowiedź impulsowa obiektu $g(\tau)$. Odpowiedź impulsowa jest również modelem nieparametrycznym w dziedzinie czasu i jej transformata Fouriera stanowi transmitancja widmowa (2):

$$
G(j \omega)=\int_{-\infty}^{\infty} g(\tau) e^{-j \omega \tau} d \tau
$$

Analogicznie do transmitancji operatorowej, transmitancję widmową można wyznaczyć ze stosunku transformaty Fouriera wyjścia do transformaty Fouriera wejścia przy zerowych warunkach początkowych (3):

$$
G(j \omega)=\frac{Y(j \omega)}{U(j \omega)}
$$

gdzie Y i U to transformaty Fouriera sygnałów u(t) i y(t). Na rysunku 1. przedstawiono w postaci wykresu Bodego transmitancję widmową badanego obiektu. Inne formy prezentacji, takie jak wykresy Nyquista czy Nicholsa, w przypadku rozpatrywanego problemu okazują się mniej przejrzyste. Pierwsza część wykresu pokazuje wzmocnienie w układzie, druga przesunięcie fazy między wejściem a wyjściem. Wynika stąd, że jeżeli badany obiekt pobudzany jest wymuszeniem harmonicznym (4) o stałej częstotliwości $\mathrm{f}=\omega / 2 \pi$ :

$$
u(t)=U \sin (\omega t+\varphi)
$$

na wyjściu generowany jest sygnał:

$$
y(t)=Y \sin (\omega t+\psi)=U|G(j \omega)| \cdot \sin [\omega t+\varphi+\operatorname{angle}(G(j \omega))]
$$



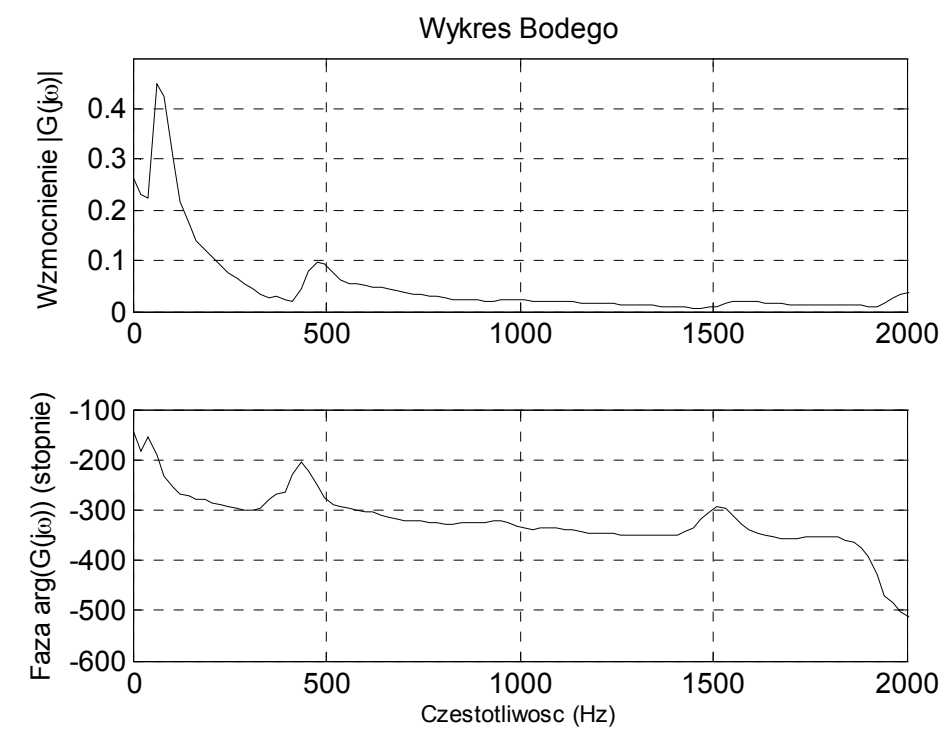

Rys. 1. Wykres Bodego badanego obiektu wibroakustycznego przedstawiający wzmocnienie oraz przesunięcie fazowe obiektu w zależności od częstotliwości wymuszenia

Wzmocnienie w układzie jest modułem, a przesunięcie fazowe jest argumentem transmitancji widmowej (5). W tym przypadku widać niejednakowe wzmocnienie obiektu, z dwoma maksimami w zakresie niskich częstotliwości oraz przesunięcie $\mathrm{w}$ fazie sygnałów.

\section{FUNKCJE KORELACJI I GĘSTOŚĆ WIDMOWA}

Odmiennym sposobem podejścia do problemu identyfikacji obiektu, jest sytuacja, kiedy dokonywana jest ona na podstawie dyskretnych sygnałów wejściowo - wyjściowych $\mathrm{u}(\mathrm{t})-\mathrm{y}(\mathrm{t})$, a nie ich ciagłych transformat. Dokonujemy pomiaru sygnału wyjściowego, podczas gdy sygnał wejściowy jest sygnałem niezakłóconym. W przeciwieństwie do wejścia, w torze pomiarowym wyjścia sygnał miesza się addytywnie $\mathrm{z}$ szumem pomiarowym. Mamy więc do czynienia $\mathrm{z}$ sygnałem stochastycznym. Powiązania statystyczne między dwoma sygnałami losowymi przedstawia funkcja korelacji. Funkcję korelacji w dziedzinie czasu określa autokorelacja lub kowariancja (korelacja wzajemna), a w dziedzinie częstotliwości gęstość widmowa (gęstość widmowa mocy). Funkcje korelacji przedstawiają się następująco [2,3]:

$$
\begin{gathered}
R_{y y\{u u\}}(k)=E[y(t)\{u(t)\} y(t \pm k)\{u(t \pm k)\}]=\frac{1}{N} \sum_{t=0}^{N-k-1} y(t)\{u(t)\} \cdot y(t \pm k)\{u(t \pm k)\} \\
R_{u y}(k)=E[u(t) y(t \pm k)]=\frac{1}{N} \sum_{t=0}^{N-k-1} u(t) \cdot y(t \pm k)
\end{gathered}
$$

Jest to więc wartość oczekiwana zmiennych losowych, którymi są wektory pomiarowe sygnałów wejścia i wyjścia. Estymatorem jest suma (6)(7), gdzie $\mathrm{N}$ to ilość próbek, a k przesunięcie sygnału. Na rysunku 2. przedstawiono wyniki analizy korelacyjnej. Dla sygnału wejściowego (Rys.2b) widzimy typowy wykres odpowiadający „białemu 
szumowi". Pełna korelacja występuje dla sygnału nieprzesuniętego w czasie, a więc w tej samej chwili. Dla sygnałów przesuniętych, nie powinny być one skorelowane, czyli $\mathrm{R}_{\mathrm{uu}}=0$. Jak wiadomo sygnał taki jest bardzo trudno wygenerować, dlatego autokorelacja jest różna od zera dla blisko położonych próbek i doży do zera wraz ze wzrostem przesunięcia. Dla sygnału wyjściowego (Rys.2a) widać wyraźną korelację co świadczy o wpływie na sygnał w danej chwili stanów obiektu $\mathrm{z}$ chwil poprzednich. Z wartości funkcji korelacji wzajemnej wynika, że sygnał wyjściowy nie jest praktycznie skorelowany z sygnałem wejściowym z chwil następnych, co w przypadku badanego obiekty jest oczywiste. Natomiast wpływ stanów wcześniejszych sygnału wejściowego na stan wyjścia pokazuje korelację ujemną. Widać przy tym większy wpływ stanów wcześniejszych wejścia na wejście tj. dla $\mathrm{k}<0$.
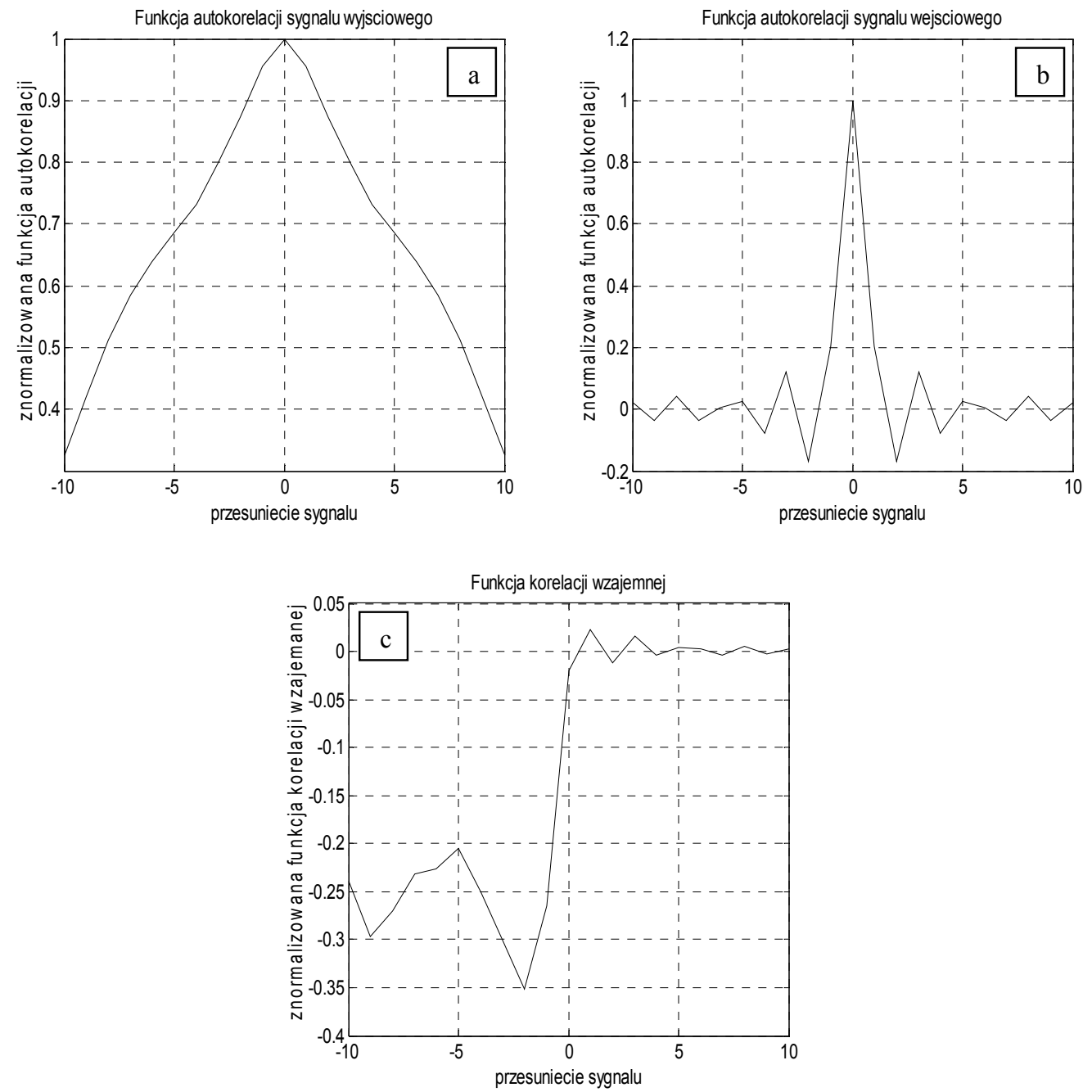

Rys. 2. Funkcje autokorelacji sygnałów wyjściowego i wejściowego oraz funkcja korelacji wzajemnej: a - $R_{y y}$ autokorelacja sygnału wyjściowego $y(t), b-R_{u u}$ autokorelacja sygnału wejściowego $u(t)$, c - $R_{\text {uy }}$ korelacja wzajemna, dla przesunięcia sygnału k od -10 (sygnał wyjścia wyprzedza wejście) do 10 (sygnał wejścia wyprzedza wejście)

Gęstość widmowa jako miara rozkładu mocy sygnału w jego widmie, określa ilość energii sygnału przypadającą na jednostkę przedziału częstotliwości, dlatego często mówi się o gęstości widmowej mocy. W przypadku, gdy na wejście obiektu podawany jest „biały szum” wiadomo, że jego gęstość widmowa mocy ma wartość stałą w całym zakresie widma. Właściwości obiektu wpływają następnie na rozkład energii na 
poszczególne częstotliwości na wyjściu. Estymatorem gęstości widmowej mocy sygnału jest zależność $[2,3]$ :

$$
P_{y y}(\omega)=\frac{1}{2 \pi} \sum_{\tau=-N}^{N} R_{y y}(\tau) e^{-j \omega \tau}
$$

Na rysunku 3 pokazano gęstości widmowe mocy sygnału wyjściowego w skali liniowej oraz logarytmicznej. Parametr $\omega$ zamieniono na częstotliwości $f=\omega / 2 \pi$. Widać, że obiekt charakteryzuje się dużą dynamiką w zakresie niskich częstotliwości.
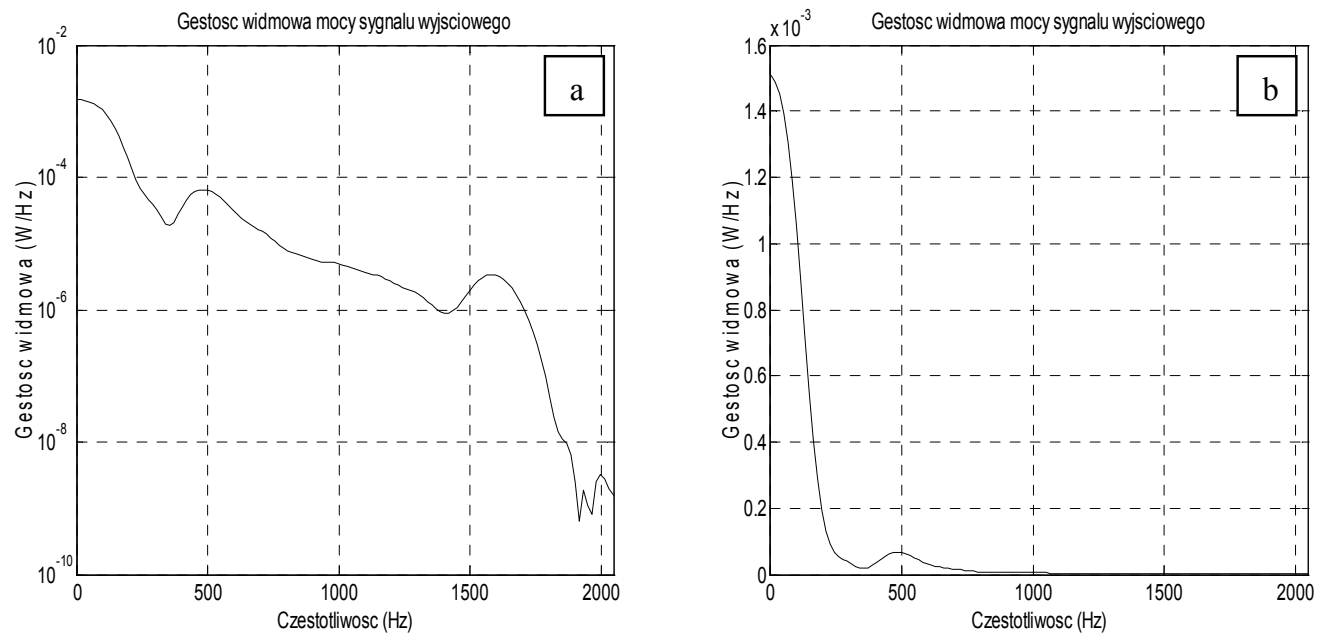

Rys. 3. Gęstość widmowa mocy badanego obiektu wibroakustycznego: a-skala logarytmiczna, b- skala liniowa

\section{WNIOSKI I DYSKUSJA WYNIKÓW}

Uzyskane modele nieparametryczne mogą być stosowane do wstępnej identyfikacji obiektów wibroakustycznych. Mimo, że modele parametryczne [4] mają bardziej zwarta formę, to z przedstawionych $\mathrm{w}$ pracy modeli nieparametrycznych można wnioskować o charakterze identyfikowanego obiektu. Na rysunku 1. przedstawiono wykres Bodego, który pokazuje niejednakowe właściwości obiektu z zakresie badanych częstotliwości tj. duże wartości wzmacniania sygnału w zakresie niskich częstotliwości $(40-100 \mathrm{~Hz}$ oraz $450-550 \mathrm{~Hz}$ ). Zgodnie $\mathrm{z}$ przewidywaniem sygnał wyjściowy, wymuszający wykazuje opóźnienie, które wzrasta wraz z częstotliwościa, aby w końcu badanego zakresu osiagnąć wartość 340 stopni. Świadczy to o zmniejszającej się dynamice obiektu wraz z częstotliwością. Wykres gęstości widmowej mocy sygnału wyjściowego (Rys.2) potwierdza powyższe obserwacje. Widać maksima lokalne mocy (,koncentracje mocy”) w zakresach częstotliwości wyszczególnionych powyżej. Pamiętając, że badanym obiektem był głośnik niskotonowy o paśmie przenoszenia do $1000 \mathrm{~Hz}$ wyniki są wiarygodne i potwierdzaja $\mathrm{w}$ tym zakresie najlepszą dynamikę. Model w postaci funkcji korelacji okazał się modelem mniej przydatnym i dostarczającym mniej istotnych danych ważnych dla obiektów wibroakustycznych. Dla konstruktorów, wyniki uzyskane tą drogą (analiza częstotliwościowa i analiza widmowa), mogą okazać się bardzo ważne. Na przykład, w tym konkretnym przypadku głośnika należałoby dążyć do uzyskania równomiernego rozkładu wzmocnienia i jak najmniejszego opóźnienia 
wyjścia, co wiąże się $\mathrm{z}$ równomiernym rozkładem mocy w całym zakresie pasma przenoszenia.

\section{LITERATURA}

1. Mańczak K., Nahorski Z.: Komputerowa identyfikacja obiektów dynamicznych, Wydawnictwo Naukowe PWN, Warszawa 1983.

2. Söderström T., Stoica P.: Identyfikacja Systemów, Wydawnictwo Naukowe PWN, Warszawa 1997.

3. Zimmer A.: Identyfikacja obiektów i sygnałów. Teoria i praktyka dla użytkowników Matlaba, Politechnika Krakowska, Kraków 1998.

4. Błażejewski A.: Identyfikacja obiektu elektro-akustycznego przy użyciu modeli parametrycznych. Konf. „LIII Otwarte Seminarium z Akustyki”, Polskie Towarzystwo Akustyczne Oddział w Krakowie, Zakopane 2006, 213-218. 